This item was submitted to Loughborough's Research Repository by the author.

Items in Figshare are protected by copyright, with all rights reserved, unless otherwise indicated.

\title{
Flexural strengthening of reinforced concrete beams using fabric reinforced alkali-activated slag matrix
}

PLEASE CITE THE PUBLISHED VERSION

https://doi.org/10.1016/j.jobe.2020.101865

PUBLISHER

Elsevier BV

VERSION

AM (Accepted Manuscript)

\section{PUBLISHER STATEMENT}

This paper was accepted for publication in the journal Journal of Building Engineering and the definitive published version is available at https://doi.org/10.1016/j.jobe.2020.101865.

\section{LICENCE}

CC BY-NC-ND 4.0

\section{REPOSITORY RECORD}

Shen, Xinyu, Weiwei Chen, Bo Li, Craig Hancock, and Yidong Xu. 2020. "Flexural Strengthening of Reinforced Concrete Beams Using Fabric Reinforced Alkali-activated Slag Matrix". Loughborough University. https://hdl.handle.net/2134/13238864.v1. 


\title{
Flexural Strengthening of Reinforced Concrete Beams Using Fabric Reinforced Alkali-Activated Slag Matrix
}

\author{
Xinyu Shen ${ }^{1}$, Weiwei Chen ${ }^{1,2}$, Bo Li ${ }^{1,2, *}$, Craig Mathew Hancock ${ }^{1}$, Yidong $\mathrm{Xu}^{3}$ \\ ${ }^{1}$ Department of Civil Engineering, University of Nottingham Ningbo China, Ningbo 315100, China \\ ${ }^{2}$ New Materials Institute, University of Nottingham Ningbo China, Ningbo 315000, China \\ ${ }^{3}$ Ningbo Institute of Technology, Zhejiang University, Ningbo 315100, China \\ *Corresponding author: bo.li@nottingham.edu.cn
}

\begin{abstract}
Old Reinforced Concrete (RC) buildings are facing different degrees of structural deterioration and require proper strengthening to enhance their structural performance as well as to extend their life span. Fabric reinforced Alkali-Activated Slag (AAS) matrix is proposed to strengthen $\mathrm{RC}$ beams in this study. Seven RC beams with and without strengthening were prepared and tested under four-point bending. Test results indicate that use of AAS matrix as replacement for conventional cement-based matrix can change the failure mode of the strengthened beams from end-debonding of strengthening layer to slippage combined with rupture of fabric. The AAS-based strengthening strategy is able to enhance the loading capacity and flexural stiffness of RC beams as well as to reduce the strain of tensile reinforcements. Except the specimens failed in the premature debonding, increasing the fabric amount in the strengthening scheme improves the loading capacity of beams. In an optimal case, the yielding and ultimate loads of the strengthened beams are enhanced by $22.2 \%$ and $26.4 \%$, respectively. Moreover, an analytical model was developed to predict the characteristic loads of the fabric reinforced AAS matrix strengthened beams. It shows that the analytical model could overestimate the yielding and ultimate loads of the strengthened beams, probably due to slippage and reduced synergistic effect of fabric bundles in the strengthening system. Based on that, two efficiency factors of 0.35 and 0.25 , taking account of the area of effective fabric, are obtained and recommended to estimate the yielding and ultimate loads of fabric reinforced AAS matrix-strengthened beams, respectively.
\end{abstract}

Keywords: alkali-activated slag, reinforced concrete beams, strengthening, carbon fabric, CFRP bar.

\section{Introduction}

A great number of existing buildings need proper rehabilitation or strengthening to enhance their structural performance as well as to extend their life span. This is mainly caused by the improper design or construction, the change of loads, and the deterioration of materials, etc. For Reinforced Concrete (RC) beams, many flexural strengthening methods have been developed in the past decades, such as externally bonding Fibre Reinforced Polymer (FRP) 
laminate [1,2], concrete jacketing [3], steel jacketing [4]. Among them, FRP laminate has the advantages over the others in terms of high strength/weight ratio, free of corrosion, and ease of construction [5]. However, the effectiveness of FRP laminate strengthening method is significantly influenced by the epoxy resin that serves as the embedding matrix for fibres and the bonding agent between the FRP laminate and the concrete substrate. The high shear stress developed at the concrete-FRP interface probably leads to the debonding failure of strengthening layer [6]. Due to the organic nature of epoxy, FRP laminate strengthening method suffers several problems, e.g. poor fire resistance, difficulty of applying on a wet surface, and incompatibility with existing concrete [7].

Several attempts have been explored to overcome the above-mentioned problems. Ebead [8] strengthened RC beams with hybrid externally bonded/mechanically fastened FRPs, and found that the use of hybrid FRPs can enhance the loading capacity and stiffness of beams as compared with epoxy bonded FRPs. Rahman et al. [9] investigated the flexural behaviour of $\mathrm{RC}$ beams strengthened with combined plate bonding and near-surface mounted (NSM) FRPs. The failure load of beam strengthened with combined plate bonding and NSM FRPs is $32 \%$ higher than that strengthened with plate bonding method. Chen et al. [10] found that attaching steel plates on FRP plates is able to improve the load-carrying capacity and ductility of RC beams. Diotallevi et al. [11] developed a thermal-resistant water-based resin as replacement for epoxy matrix for FRP, and found that both resins exhibit similar effectiveness on enhancing the structural performance of RC beams. Majhi et al. [12] evaluated the structural performance of the FRP-strengthened beams with alkali-activated siliceous paste and epoxy resin as the bonding agent. It was found that the alkali-activated siliceous-bonded FRP strengthening method exhibit better high-temperature resistance than the conventional epoxy-based strengthening method. At a temperature of $100^{\circ} \mathrm{C}$, the beam strengthened with alkali-activated siliceous system possesses nearly 33\% higher loading capacity than that with the epoxy resin. Similarly, Zhang et al. [13] compared the load-deflection behaviour of RC beams retrofitted with epoxy or geopolymer-bonded carbon FRP. The beam strengthened with geopolymer-based FRP achieves a better fire resistance as it exhibits a lower deflection than that with epoxy-based FRP. Overall, it has demonstrated that cementitious material can be used to substitute the conventional epoxy as an alternative bonding agent in the FRP strengthening method. However, it could probably affect the efficiency of FRP strengthening method due to the reduced bonding between the FRP laminate and the concrete substrate.

Recently, Fabric Reinforced Cementitious Matrix (FRCM) has been developed as an alternative strengthening or repair system for RC structures [14,15]. Compared with the FRP, the FRCM possesses the advantages of high-temperature resistance, low cost, applicability under low temperature or on wet concrete surface, permeability to water vapours, and compatibility with concrete substrate [7]. Those advantages are mainly associated with the avoidance of epoxy in the strengthening system. The effectiveness of FRCM strengthening method is significantly affected by characteristics of fabric [16,17], impregnation quality of matrix into fabric [18], and coating condition of fabric [19]. Truong et al. [20] tested twelve RC beams strengthened with FRCM, and reported that externally applied FRCM layer can 
increase the ultimate load of RC beams by $27 \%$. Aljazaeri et al. [21] evaluated the structural performance of FRCM-strengthened beams with glass spike or U-wrapped anchorage system. The use of anchorages is effective in shifting the failure mode of the strengthened beams from end-debonding of FRCM to slippage of fabric, leading to $21 \%$ enhancement of ultimate load. Irshidat and Al-Shannaq [22] added carbon nano-tubes into the matrix of FRCM, and reported that the addition of carbon nano-tube has marginal impact on the flexural capacity of the strengthened beams, but evidently enhances their flexural stiffness.

Nevertheless, the application of FRCM system consumes a large amount of Ordinary Portland Cement (OPC) whose production has become one of the main sources responsible for greenhouse gas emissions in the construction industry. On the other hand, alkali-activated material has been recognised as a promising binder to replace the OPC due to its better mechanical properties [23], sulphate resistance [24], and fire resistance [25]. Although there are many studies focusing on the properties of alkali-activated materials, the research in the use of alkali-activated material-based matrix in FRCM system remains limited. Menna et al. [26] strengthened shallow beams with carbon or steel fabric reinforced geopolymer, and reported that the use of steel fabric reinforced geopolymer can significantly enhance the loading capacity of RC beams by $100 \%$. Al-Majidi et al. [27] also adopted geopolymer as the matrix of fabric or steel bars to strengthen RC beams, and reported that the beam strengthened with steel bars reinforced geopolymer exhibits doubled ultimate load as compared with the control beam. These studies mainly focus on the use of fly ash-based geopolymer as the matrix for fabric. the use of fabric reinforced Alkali-Activated Slag (AAS) as strengthening method for $\mathrm{RC}$ structures has drawn little attention, despite that AAS has advantages over geopolymer such as higher early strength [28].

In this study, the effectiveness of fabric reinforced AAS matrix for flexural strengthening of $\mathrm{RC}$ beams is investigated. Flexural tests on RC beams with or without strengthening were conducted to compare their failure mode, loading capacity, stiffness, and strain of tensile reinforcements. The influence of matrix type, fabric bundle size, total fabric amount, and form of reinforcement in the strengthening scheme on the flexural behaviour of RC beams was estimated. Moreover, an analytical model was proposed to predict the yielding and ultimate loads of beams strengthened with the fabric reinforced AAS matrix.

\section{Experimental program}

\subsection{Matrix}

OPC mortar and AAS mortar were used as the matrix in the strengthening method and their mix formulations are given in Table 1. For the binder, grade 42.5 cement was selected for the OPC mortar, while ground granulated blast-furnace slag blended with fly ash was used for the AAS mortar. The mass ratio of slag to fly ash was fixed at 7:3 to ensure a suitable workability and volumetric stability of AAS mortar [29]. The activator for AAS was prepared by dissolving the solid sodium hydroxide into water, which was then blended with water glass solution. The water glass solution comprises $26.83 \% \mathrm{SiO}_{2}, 8.32 \% \mathrm{Na}_{2} \mathrm{O}$, and $64.85 \% \mathrm{H}_{2} \mathrm{O}$ by mass. The alkali dosage of the activator was fixed at $4 \% \mathrm{Na}_{2} \mathrm{O}$ by mass of binder while the mass ratio of 
$\mathrm{SiO}_{2} / \mathrm{Na}_{2} \mathrm{O}$ in the activator was 1.5 . The prepared alkali activator had been cooled down to room temperature before it was used for preparing AAS mortar. Sand with the maximum particle size of $2.36 \mathrm{~mm}$ was used as aggregate in both OPC and AAS mortars. Polypropylene fibres were added at a volume fraction of $1.0 \%$ to mitigate the dry shrinkage [30] and improve the bond between the fabric and the matrix [31]. Compressive tests were conducted for the OPC and AAS matrixes on the same day for testing of RC beams. The average compressive strength of OPC and AAS matrixes are $52.8 \mathrm{MPa}$ and $53.5 \mathrm{MPa}$, respectively.

Table 1. Mix formulation of OPC and AAS matrix.

\begin{tabular}{cccccc}
\hline Matrix & $\begin{array}{c}\text { Binder } \\
\left(\mathrm{g} / \mathrm{cm}^{3}\right)\end{array}$ & $\begin{array}{c}\text { Water } \\
\left(\mathrm{g} / \mathrm{cm}^{3}\right)\end{array}$ & $\begin{array}{c}\text { Alkaline activator } \\
\left(\mathrm{g} / \mathrm{cm}^{3}\right)\end{array}$ & $\begin{array}{c}\text { Sand } \\
\left(\mathrm{g} / \mathrm{cm}^{3}\right)\end{array}$ & $\begin{array}{c}\text { Fibre } \\
\left(\mathrm{g} / \mathrm{cm}^{3}\right)\end{array}$ \\
\hline OPC mortar & 1.048 & 0.346 & - & 1.310 & 0.009 \\
AAS mortar & 1.048 & - & 0.436 & 1.310 & 0.009 \\
\hline \multicolumn{2}{l}{ Note: the mass of alkaline activator includes the water in $\mathrm{NaOH}$ solution and water glass. } \\
\hline
\end{tabular}

\subsection{Reinforcement in matrix}

Carbon fabric and FRP bars shown in Figure 1 were adopted as the reinforcements in the strengthening scheme. Two types of fabric with different cross section areas of a single bundle, namely S-type and L-type, were used. They have a mesh size of $20 \mathrm{~mm}$ in both warp and weft directions. The cross-section area of a single bundle in the S-type and L-type fabric is 0.89 $\mathrm{mm}^{2}$ and $2.23 \mathrm{~mm}^{2}$, respectively. The FRP bars with a diameter of $6 \mathrm{~mm}$ were spirally wrapped with glass fibre string to enhance the roughness of surface. Table 2 gives geometrical and mechanical properties of carbon fabric and FRP bars provided by the manufacturer.

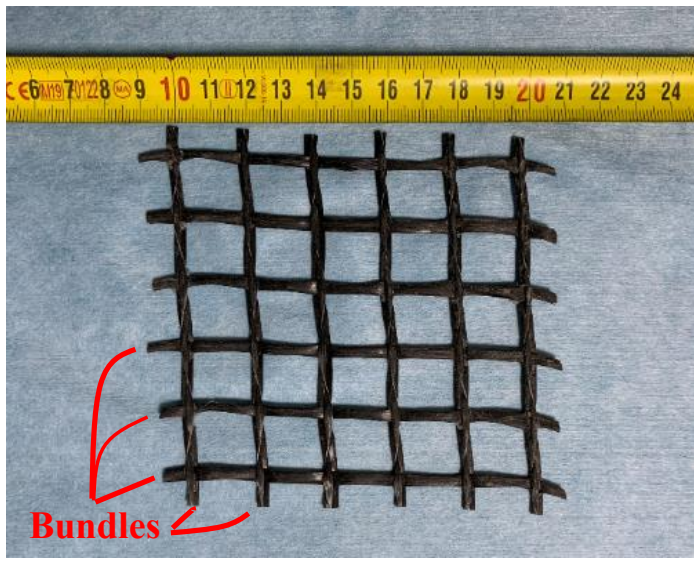

(a)

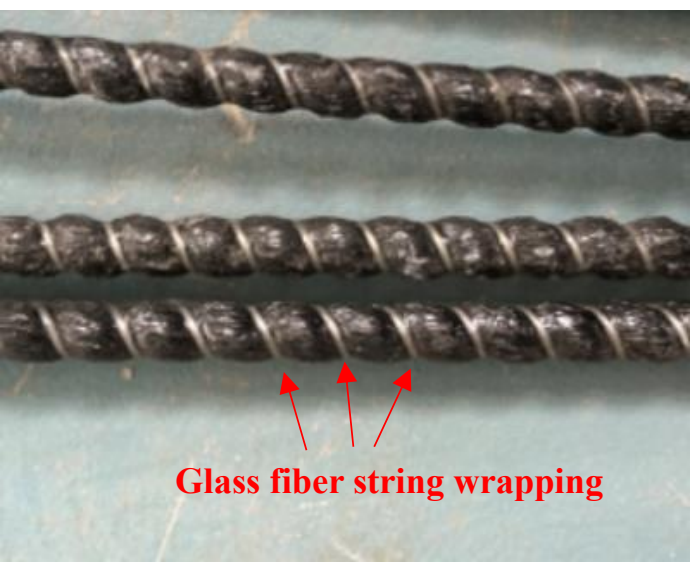

(b)

Figure 1. Reinforcements for the strengthening scheme: (a) CFRP fabric and (b) CFRP bars.

Table 2. Properties of carbon fabric and FRP bar

\begin{tabular}{cccccc}
\hline Reinforcement & $\begin{array}{c}\text { Area per } \\
\text { bundle/bar } \\
\left(\mathrm{mm}^{2}\right)\end{array}$ & $\begin{array}{c}\text { Spacing of } \\
\text { bundles } \\
(\mathrm{mm})\end{array}$ & $\begin{array}{c}\text { Tensile } \\
\text { strength } f_{u} \\
(\mathrm{MPa})\end{array}$ & $\begin{array}{c}\text { Elastic } \\
\text { modulus } E_{f} \\
(\mathrm{GPa})\end{array}$ & $\begin{array}{c}\text { Rupture } \\
\text { strain } \varepsilon_{u} \\
(\%)\end{array}$ \\
\hline
\end{tabular}




\begin{tabular}{|c|c|c|c|c|c|}
\hline S-type fabric & 0.89 & 20 & 2,300 & 240 & 0.96 \\
\hline L-type fabric & 2.23 & & & & \\
\hline Bar & 28.26 & N/A & 1,800 & 120 & 1.5 \\
\hline
\end{tabular}

\subsection{Fabric reinforced AAS matrix}

Tensile properties of fabric reinforced AAS matrix were evaluated by a uniaxial tensile test. Figure 2 shows the geometry of fabric reinforced AAS matrix coupon and the corresponding uniaxial tensile test setup. Both ends of the coupon were gripped by the clamping wedges, while the gripping regions of the coupon were bonded with aluminium tabs for applying a uniform stress. Two linear variable displacement transducers (LVDTs) were installed with a gauge length of $150 \mathrm{~mm}$ on the coupon to measure its extension. Four groups of fabric reinforced AAS matrix coupons with different types of matrix, fabric, sectional area of fabric were prepared and tested as shown in Table 3. Three coupons were included in each group. The uniaxial tensile load was applied in the displacement-control mode with a constant rate of 0.5 $\mathrm{mm} / \mathrm{min}$.
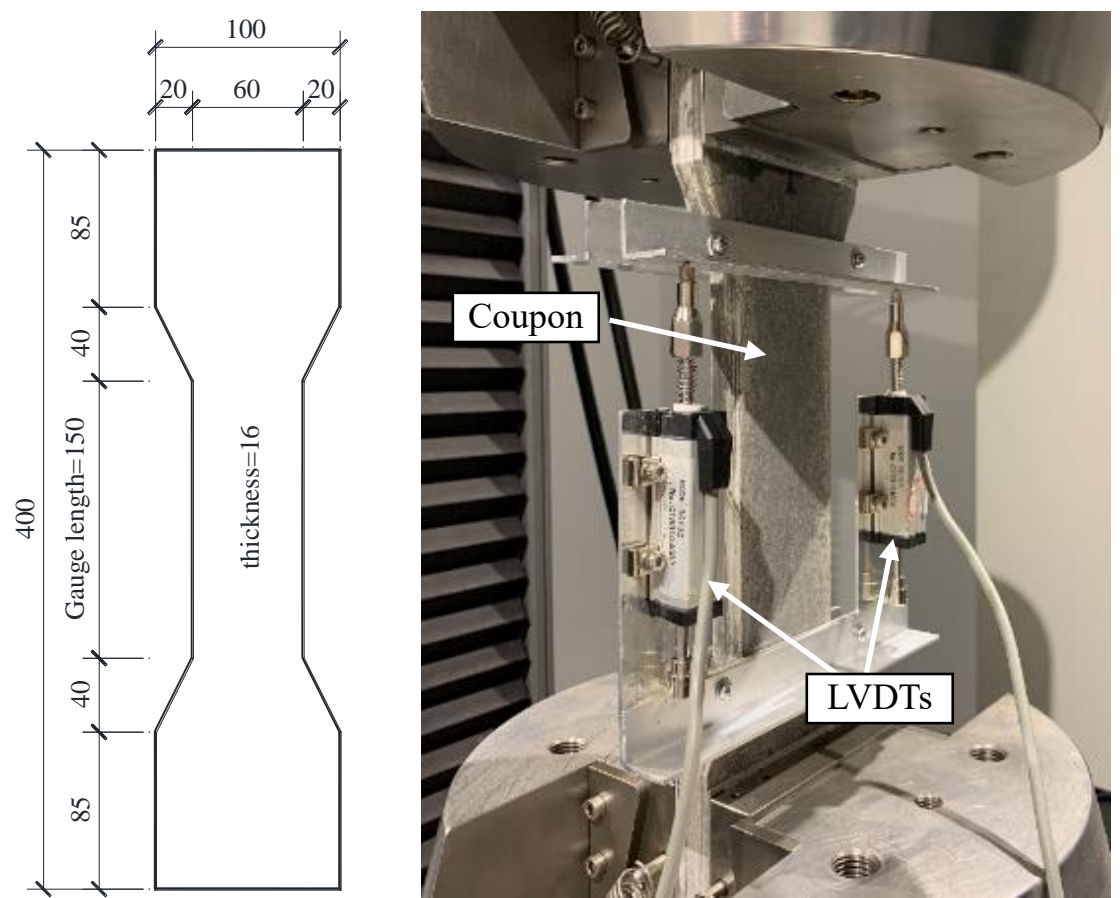

Figure 2. Geometry of fabric reinforced AAS matrix coupons and test setup (unit: $\mathrm{mm}$ ).

Table 3. Summary of fabric reinforced AAS matrix coupons.

\begin{tabular}{cccccc}
\hline Group & Matrix & Fabric & Number of bundles & $A_{f}\left(\mathrm{~mm}^{2}\right)$ & $\rho_{f}(\%)$ \\
\hline OS1A & OPC & S-type & 10 & 8.9 & 0.93 \\
AS1A & AAS & S-type & 10 & 8.9 & 0.93 \\
AL1A & AAS & L-type & 4 & 8.9 & 0.93 \\
AL2A & AAS & L-type & 8 & 17.8 & 1.85 \\
\hline
\end{tabular}

- $A_{f}$ : sectional area of fabric bundles;

- $\rho_{f}$ : ratio of $A_{f}$ divided by the gross section of the coupon; 


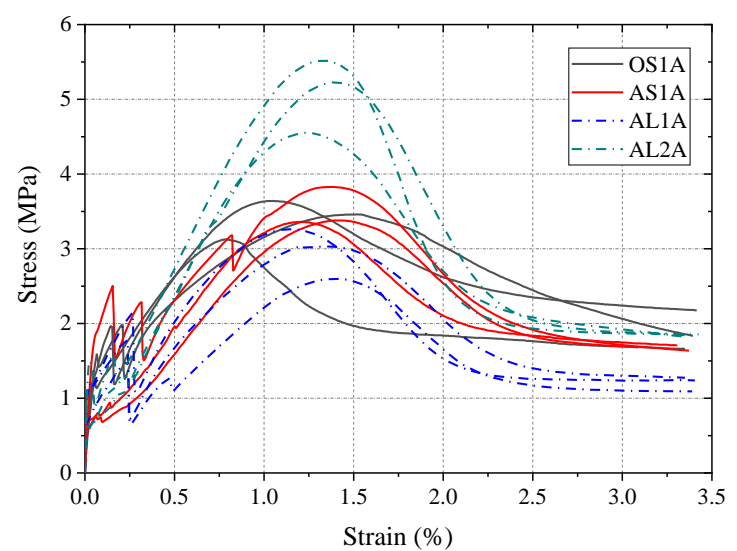

(a)

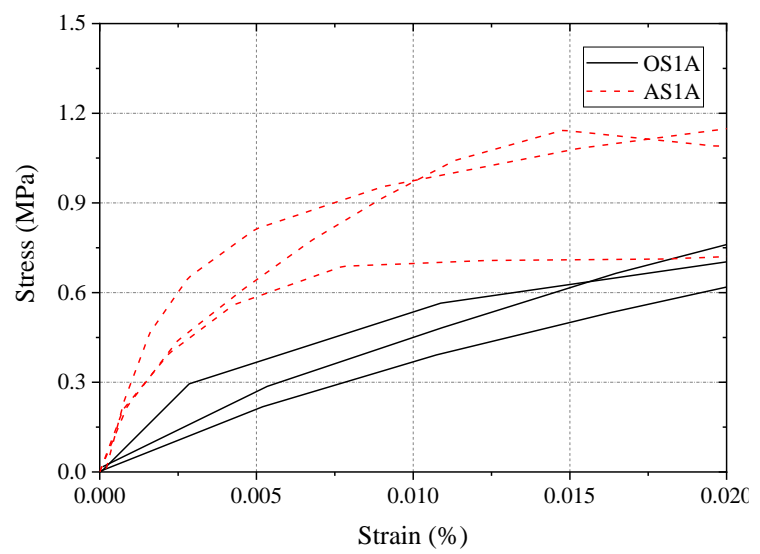

(b)

Figure 3. Stress-strain relationship of fabric reinforced AAS/OPC matrix coupons.

Figure 3(a) shows the tensile stress-strain relationships of fabric reinforced AAS/OPC matrix coupons. The stress is calculated through dividing the tensile force by the gross sectional area of the coupon, while the strain is determined through dividing the extension recorded by LVDTs by the gauge length. In general, the stress-strain curves of fabric reinforced AAS/OPC matrix can be characterized by four stages, including the elastic stage before matrix cracking, the multiple cracking stage with the fluctuation of stress, the ascending stage when the fabric bundles take most load, and the descending stage corresponding to the failure of coupons due to the fabric slippage. For the most fabric reinforced AAS/OPC matrix coupons, the peak tensile stress is achieved at a strain between $1 \%$ and $1.5 \%$. The peak stress of fabric reinforced AAS matrix increases with the amount of fabric. In addition, the tensile behaviour of fabric reinforced OPC and AAS matrix can be differentiated by the initial stiffness of groups OS1A and AS1A as shown in Figure 3(b).The fabric reinforced AAS matrix has a higher stiffness than the fabric reinforced OPC matrix.

\subsection{RC beams}

Seven RC beams, including one control specimen and six strengthened specimens, were prepared and tested. The beams with a total length of 2,400 $\mathrm{mm}$ have an identical cross-section of $150 \mathrm{~mm}$ (width) $\times 250 \mathrm{~mm}$ (height). They are designed to achieve a ductile flexural behaviour of beams. In this case, two D12 steel rebars and two D8 steel rebars are adopted as the tensile and compressive reinforcements, respectively. The concrete cover is controlled at $20 \mathrm{~mm}$. To prevent shear failure, D8 stirrups are intensively arranged with a spacing of 100 $\mathrm{mm}$ along the beam. The tensile reinforcement ratio $\rho_{s}$ defined as $A_{s} /\left(b h_{0}\right)$ is $0.69 \%$, where $A_{s}$ is the area of tensile reinforcements, $b$ is the width of the section, and $h_{0}$ is the depth of tensile reinforcement. Tensile and compression tests were conducted to measure the properties of steel bars and concrete, respectively. The yielding strengths of D8 and D12 steel bars are $455.3 \mathrm{MPa}$ and $479.1 \mathrm{MPa}$, respectively. The 28-day cubic compressive strength $f_{c u}$ of concrete is 23.8 $\mathrm{MPa}$. Geometry and reinforcement details of RC beams are shown in Figure 4. 


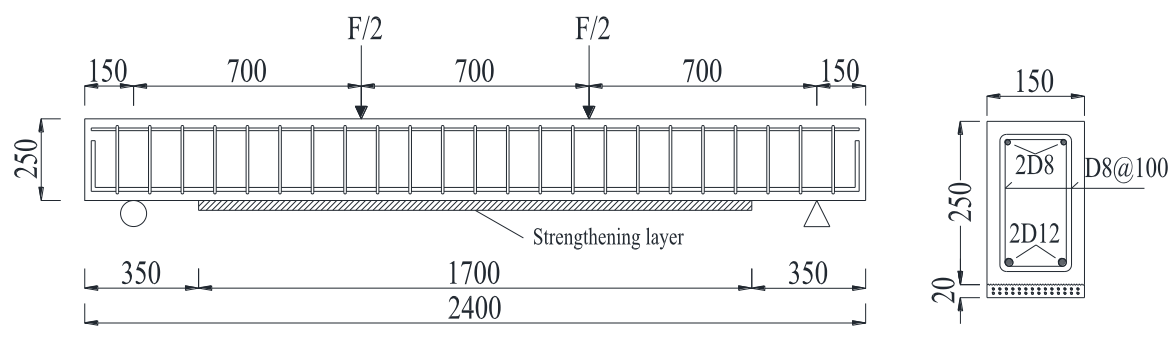

Figure 4. Geometry and reinforcement detail of RC beams.

\subsection{Strengthening scheme}

The RC beams were strengthened by externally applying carbon fabric or FRP bars reinforced matrix to the beam soffit. To fully utilize the area of beam substrate, the strengthening layer has the same width as the beam. A typical thickness for FRCM system of $20 \mathrm{~mm}$ is adopted for the strengthening layer [32]. To provide sufficient anchorage, the strengthening layer is extended close to the beam ends, with a total length of $1,700 \mathrm{~mm}$. Figure 5 shows the sectional view of the strengthening layers with different arrangements of fabric or bars.

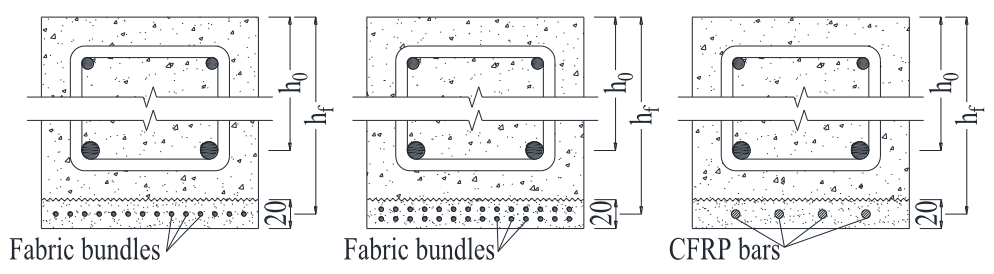

Figure 5. Sectional view of the strengthened beams.

The application procedure of carbon fabric or bars reinforced AAS/OPC matrix for strengthening of RC beams is shown in Figure 6. The concrete surface was first roughened by an electrical bush hammer to remove the superficial mortar and was then cleaned by a vacuum cleaner. After saturating the cleaned surface with water, the first layer of matrix was cast. Carbon fabric or FRP bars were then placed and slightly tapped into the matrix. The above casting and installation steps were repeated if multiple layers of fabric were adopted in the strengthening scheme. The last layer of matrix was subsequently applied. The strengthening layer was covered with a plastic film and cured at an ambient temperature.

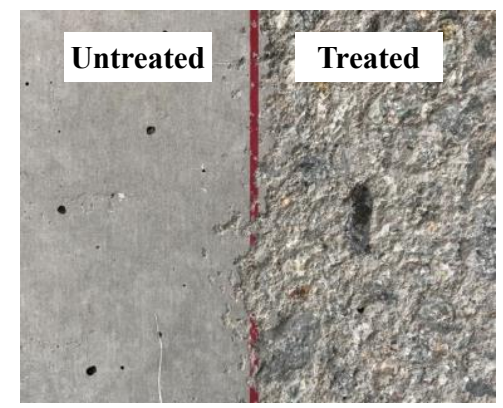

(a) Surface preparation

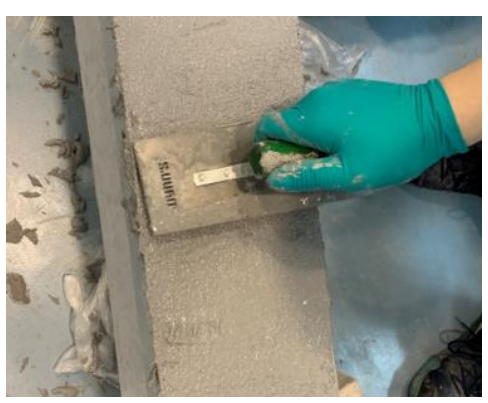

(b) Casting base matrix layer

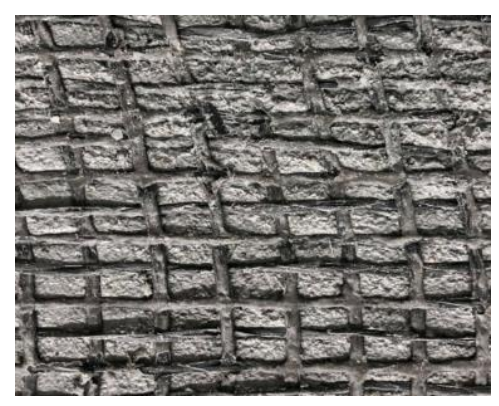

(c) Impregnation of fabric 


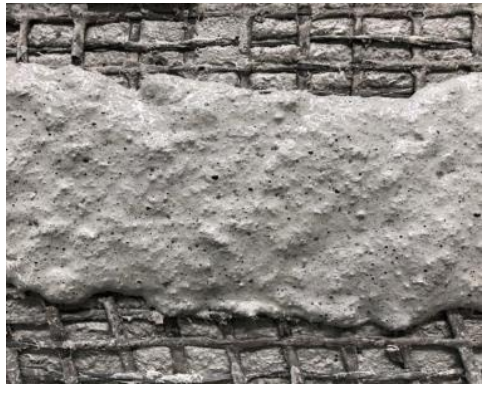

(d) Casting new matrix layer

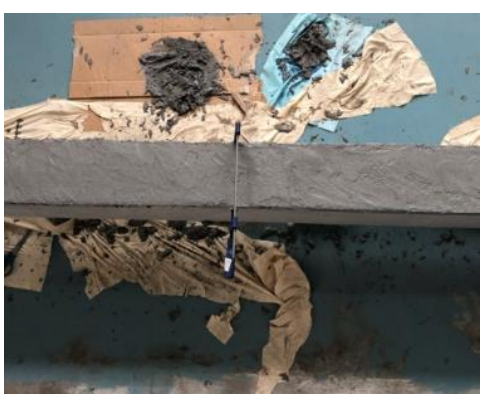

(e) Casting completion

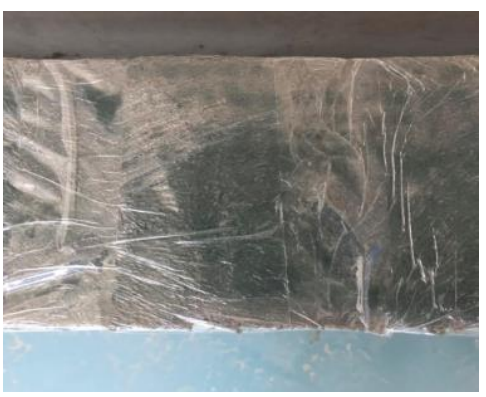

(f) Sealing for curing

Figure 6. Strengthening procedure for RC beams.

Table 4 summarizes the RC beam specimens with various strengthening schemes. The names of specimens indicate their strengthening scheme, starting with B for beam, followed by the matrix type, the matrix reinforcement type and the total area of fabric. The area of fabric $A_{0}$ was determined as $39.9 \mathrm{~mm}^{2}$, considering the geometry of fabric and constructability of the strengthening method. The equivalent reinforcement ratio defined as $\rho_{e q}=\rho_{s}+\rho_{\text {ext }}\left(E_{\text {ext }} / E_{s}\right)$ is also calculated and given in Table 4, where $\rho_{s}$ and $\rho_{\text {ext }}$ are the reinforcement ratios of $A_{s}$ (i.e. area of steel bars) and $A_{\text {ext }}$ (i.e. area of fabric or CFRP bars) over their corresponding effective sectional area, respectively [26]. Specimen B-A-Bar with four $6 \mathrm{~mm}$ diameter CFRP bars has a similar equivalent reinforcement ratio as specimen $\mathrm{B}-\mathrm{A}-\mathrm{L}-1.5 \mathrm{~A}_{0}$.

Table 4. Summary of RC beam specimens.

\begin{tabular}{cccccc}
\hline Specimen & Matrix & Reinforcement & Number of bundles & $\begin{array}{c}\text { Aext } \\
\left(\mathrm{mm}^{2}\right)\end{array}$ & $\begin{array}{c}\rho_{\text {eq }} \\
(\%)\end{array}$ \\
\hline B-C & N/A & N/A & N/A & N/A & 0.70 \\
\hline B-O-S-A 0 & OPC & S-type fabric & 45 & 40 & 0.82 \\
\hline B-A-S-A 0 & AAS & S-type fabric & 45 & 40 & 0.82 \\
\hline B-A-L-A 0 & AAS & L-type fabric & 18 & 40 & 0.82 \\
\hline B-A-L-1.5A 0 & AAS & L-type fabric & 27 & 60 & 0.88 \\
\hline B-A-L-2A 0 & AAS & L-type fabric & 36 & 80 & 0.94 \\
\hline B-A-Bar & AAS & CFRP Bar & 4 & 113 & 0.87 \\
\hline
\end{tabular}

\subsection{Test setup and instrumentation}




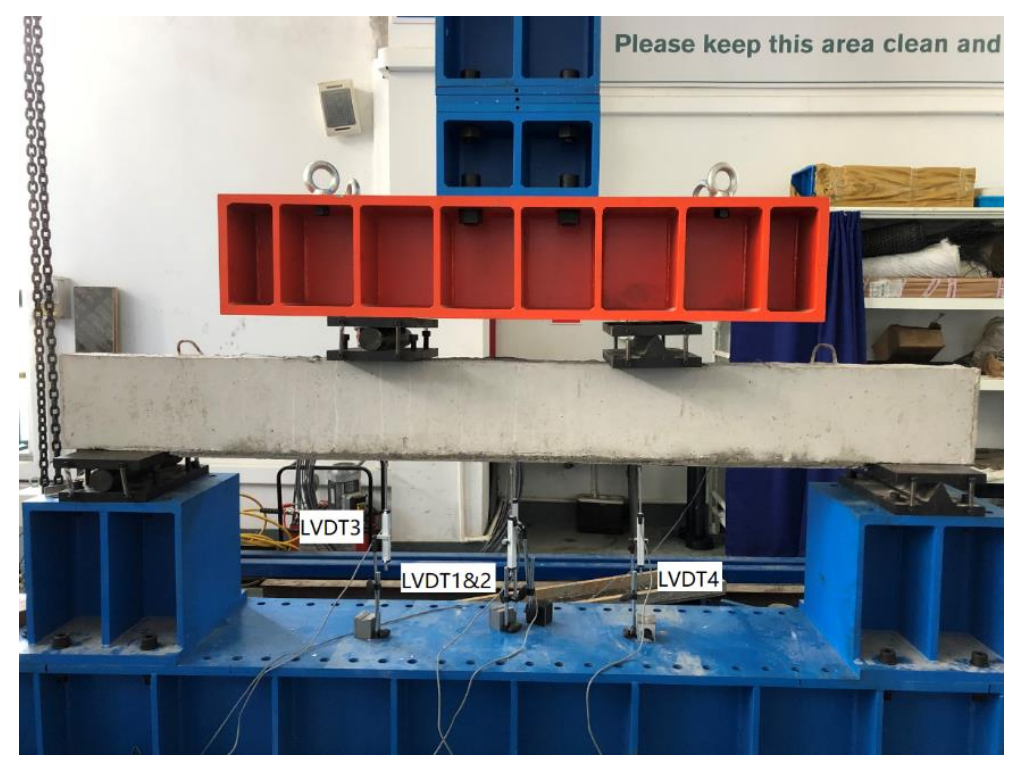

Figure 7. Test setup for RC beams

Figure 7 shows the test setup for a four-point bending test of RC beams. The beam was simply supported with a clear span of 2,100 mm. A vertical load was monotonically applied through a load-transfer beam, resulting in a $700 \mathrm{~mm}$ long pure-bending zone in the middle of beam. The load was applied in a constant rate of $1.5 \mathrm{~mm} / \mathrm{min}$. To monitor and evaluate structural response of the beams, four LVDTs were installed to record the deflection of beam at the middle span and the loading points. Moreover, two strain gauges were installed on the tensile reinforcements at middle of the beam to monitor their strains. Data from LVDTs and strain gauges was recorded by a data acquisition system with a frequency of $1 \mathrm{~Hz}$.

\section{Experimental results and discussion}

\subsection{Crack pattern and failure mode}

Figure 8 shows the crack patterns and failure modes of the RC beams with and without strengthening. As shown in Figure 8(a), the control specimen failed in a typical flexural mode for ductile RC beam. Cracks first appeared in the tensile zone at the mid-span of the beam. The yielding of longitudinal reinforcements subsequently occurred as the deflection increased, followed with the crushing of concrete in the compression zone. For the strengthened beams, tensile cracks were first found at the tensile zone of concrete, followed with the occurrence of matched cracks at the strengthening layer as shown in Figure 9(a). This indicates that the strengthening layer has a better capacity in crack control, which is probably contributed to the addition of chopped fibres in the strengthening matrix [33]. After entering the yield stage, the strengthened beams showed different crack patterns and failure modes, particularly at the interface between the strengthening layer and concrete substrate.

For the beam strengthened with fabric reinforced OPC matrix (i.e. specimen B-O-S-A0), debonding of the strengthening layer occurred at the interface between matrix and concrete from its ends when the deflection researched around $9.0 \mathrm{~mm}$. However, the beam strengthened with fabric reinforced AAS matrix (i.e. in specimen B-A-S-A 0 ) failed with slippage combined with rupture of fabric. This indicates that replacing OPC matrix with AAS matrix can change 
the failure mode from the end-debonding of strengthening layer to the rupture of fabric as shown in Figure 9(b). This improvement could be attributed to the better bonding of AAS matrix with concrete substrate as the same fabric was used in both strengthening schemes. The change of failure mode also indicates the better utilization of strength of fabric in the strengthening system.

(a) B-C

(b) B-O-S-A

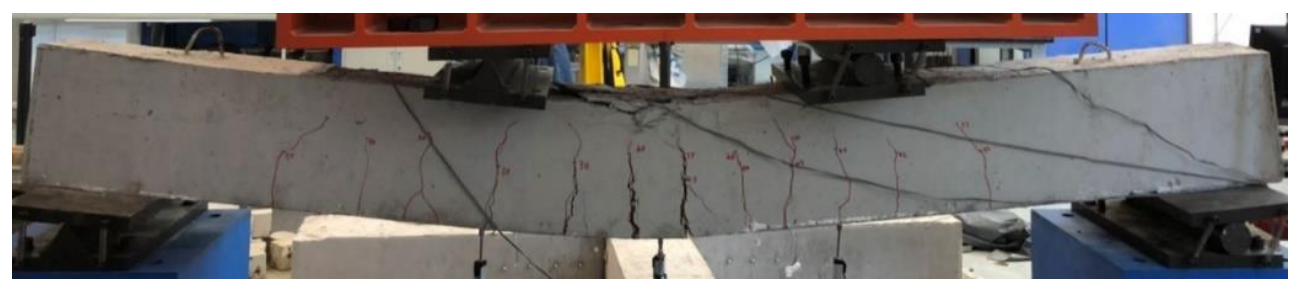

(c) B-A-S-A

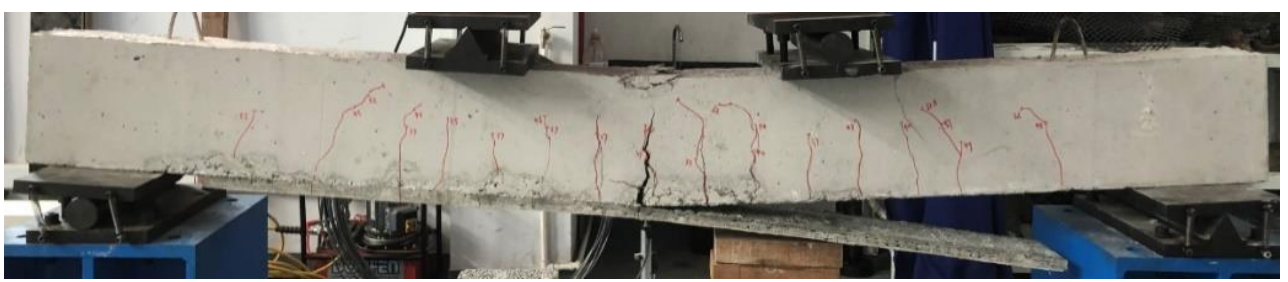

(d) B-A-L-A

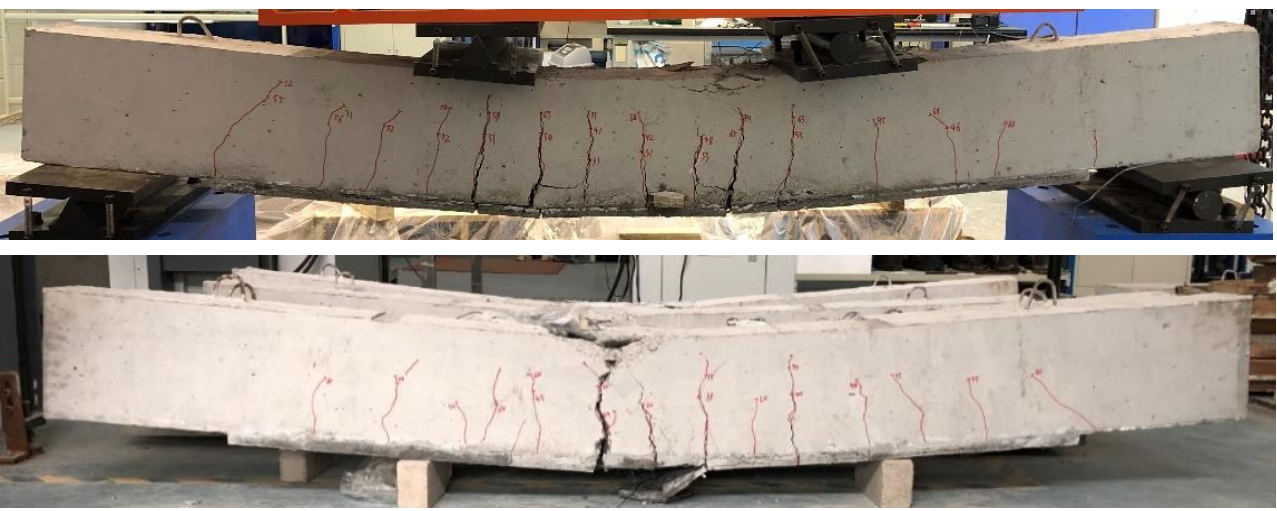

(e) B-A-L-1.5 $\mathrm{A}_{0}$

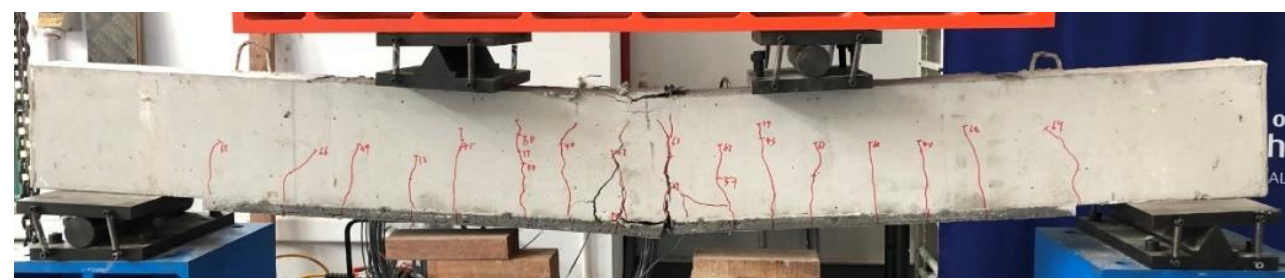

(f) B-A-L-2A

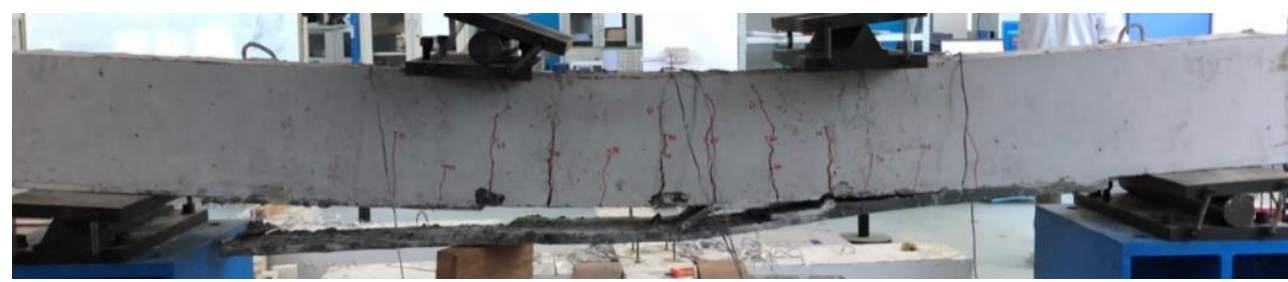

(g) B-A-Bar

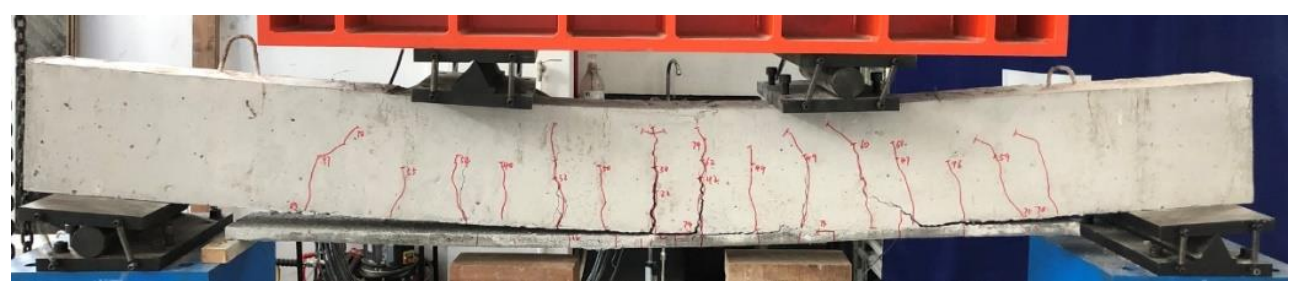

Figure 8 . Final crack patterns and failure modes of beams.

The beams strengthened with L-type fabric with cross section areas of $A_{0}$ and $1.5 A_{0}$ also failed 
by slippage combined with rupture of fabric in the strengthening layers. However, further increasing the cross-section area of fabric to $2 A$ o triggered the debonding between matrix and fabric layer as shown in Figure 9(c). This failure mode typically occurs when dense fabrics are used in fabric reinforced AAS matrix [34], which decreases the efficiency of the strengthening system. The use of CFRP bars in the strengthening system also changed the failure mode of beam back to the debonding of strengthening layer at the matrix-concrete interface. Comparing specimens B-A-L-1.5A0 and B-A-Bar with similar equivalent reinforcement ratio, the different failure mode could be attributed to the rough surface of CFRP bars that prevented the local slippage of CFRP bars against matrix. Hence, the stress developed on the matrix-concrete interface is higher and exceeded the bonding capacity, resulting in the debonding of the whole strengthening layer. It suggests that anchorage method should be provided in order to further utilize the capacity of CFRP bars in the AAS-based strengthening system.

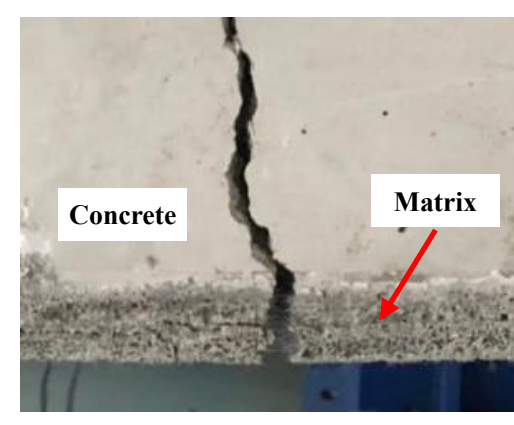

(a) matched crack

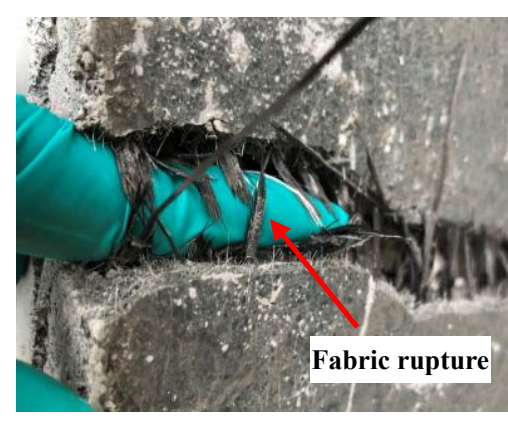

(b) fabric rupture

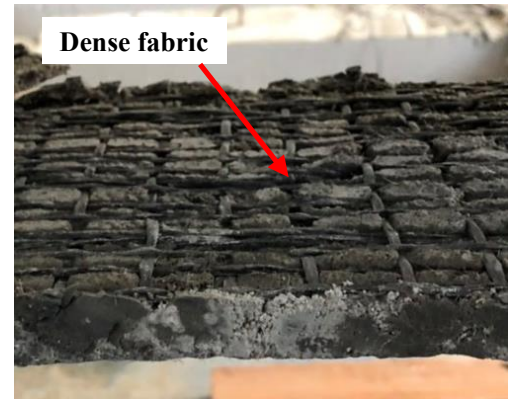

(c) interlaminate debonding

Figure 9. Failure characteristics of strengthening layer.

\subsection{Load-deflection behaviour}

Figure 10 shows the load-deflection curves for RC beams with and without strengthening. The load-deflection curve for control specimen represents a ductile flexural behaviour which consists of elastic, cracking and yielding stages. Generally, the strengthened beams exhibit enhanced performance in terms of ultimate load and stiffness, particularly at the yielding stage. The load of the strengthened beams evidently drops after reaching the ultimate load. This is mainly caused by the premature debonding of strengthening layer or the combined slippage and rupture of fabric in the strengthening system. Afterwards, the load-deflection behaviour of the strengthened beams tends to be consistent with that of control specimen.

Figure 10(a) shows the load-deflection behaviour of control beam and the beams strengthened with fabric reinforced OPC or AAS matrix. Specimen B-O-S-A 0 exhibits a slight improvement in loading capacity over the control specimen at the yielding stage, followed with a sudden drop in load due to the premature end-debonding at the concrete-matrix interface. As the horizontal debonding crack propagates towards middle span of the beam, the load fluctuates as the deflection increases. Once the debonding crack connects to the concrete tensile crack, the load-deflection curve tends to be stable. With the better bonding of AAS with concrete, specimen B-A-S-A 0 shows a higher loading capacity attained at a larger deflection. For instance, the first significant decrease in load happens at the deflection of $15 \mathrm{~mm}$. However, slippage 
and progressive rupture of fabric in the strengthening system results in repeated drop in load, and finally causes total failure of the strengthening layer.

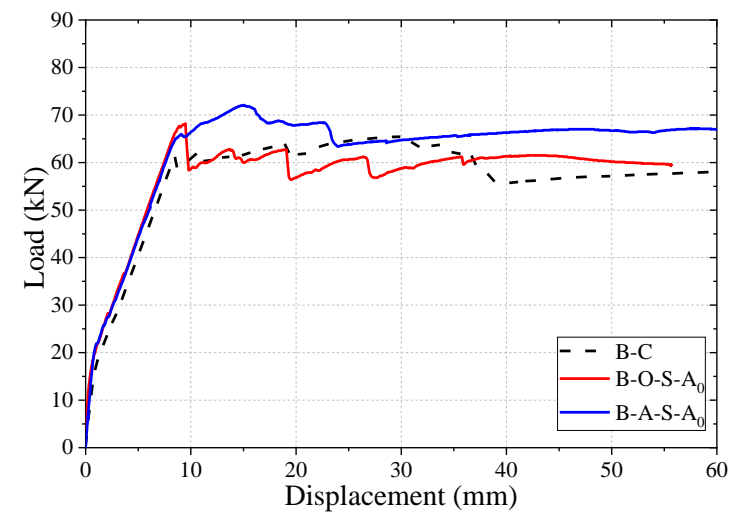

(a)

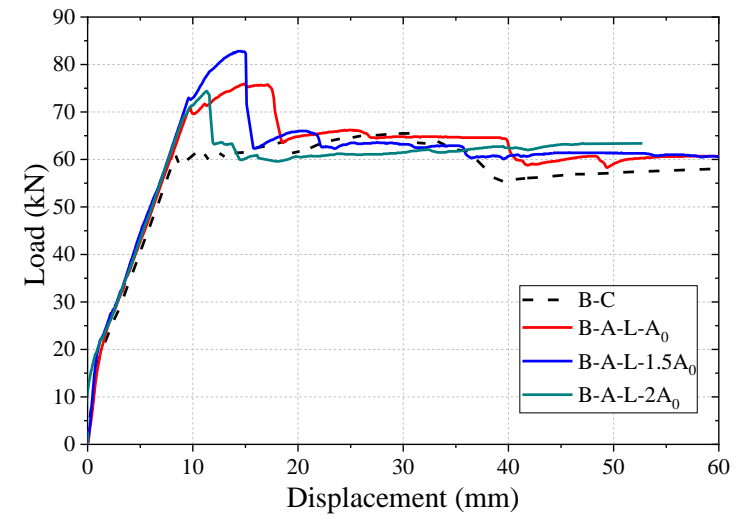

(c)

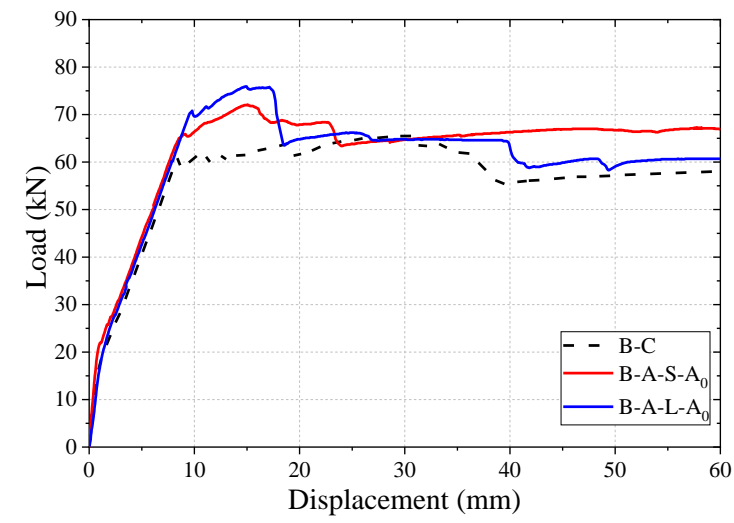

(b)

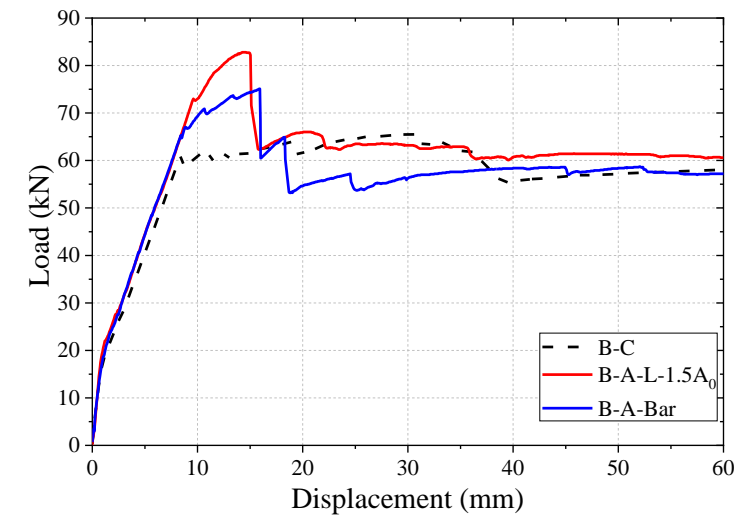

(d)

Figure 10. Load-deflection curves for RC beams with different (a) types of matrix, (b) types of fabric, (c) amounts of fabric, and (d) forms of reinforcement.

Figure 10(b) compares the load-deflection relationships of RC beams strengthened with S-type or L-type fabric reinforced AAS matrix. Comparing to the small-section fabric, the use of largesection fabric in the strengthening system improves the ultimate load of the strengthened beams. This is attributed to the better synergistic effects of bundles in the large-section fabric. For a given cross-section area of fabric, there are more bundles in the S-type fabric that might not be able to simultaneously take load. Therefore, there are gradual drops in the load-deflection curve for specimen B-A-S-A 0 as the bundles progressively ruptured. On the other hand, the load drop for specimen B-A-L-A $\mathrm{A}_{0}$ is larger than that for specimen B-A-S-A $\mathrm{A}_{0}$, which is caused by the higher force sustained by each single large-section bundle. Overall, fabric with large-size bundles is preferred for the proposed strengthening system.

Figure 10(c) shows the load-deflection behaviour of RC beams with different amounts of fabric in the strengthening system. Increasing fabric content from $A_{0}$ to $1.5 A_{0}$ enhances the ultimate load of RC beam, although the enhancement is not proportional to the amount of fabric. It can be found that specimen $\mathrm{B}-\mathrm{A}-\mathrm{L}-1.5 \mathrm{~A}_{0}$ achieves a higher ultimate load at a lower deflection as compared with specimen B-A-L-A $\mathrm{A}_{0}$. A tremendous fluctuation in load-deflection curves indicates the progressive rupture of fabric inside the strengthening layer. Afterwards, tensile 
force was redistributed to the steel rebars and finally the load-deflection curve tends to be consistent with that of control specimen. However, further increasing fabric amount to $2 \mathrm{Ao}$ decreases the ultimate load and its corresponding deflection. This is in agreement with the experimental observation that the overly added fabric brings the interlaminate debonding between matrix and fabric layers.

Figure 10(d) compares the load-deflection curves of the beams strengthened with a similar equivalent reinforcement ratio of carbon fabric or FRP bars. The two strengthening schemes have nearly identical impact on the load-deflection curve before entering their yielding stage. Afterwards, the beam strengthened with CFRP bars (i.e. specimen B-A-Bar) shows a slower increase of load. When the deflection reaches about $15 \mathrm{~mm}$, their load-deflection curves show dramatic drops of load due to the failure of strengthening layers. The observed debonding of strengthening layer in specimen B-A-Bar causes the first significant drop in load. As the debonding penetrates towards middle span of the beam, there is another minor drop in load. After the failure of strengthening layers, both strengthened specimens exhibit similar loaddeflection responses as the control specimen.

\subsection{Characteristic loads}

Based on the load-deflection curves, cracking load $F_{c}$, yielding load $F_{y}$ and ultimate load $F_{u}$ of the beams are obtained and summarized in Table 5. Here, the cracking load $F_{c}$ is defined as the load corresponding to occurrence of first flexural crack during the test. The yielding load $F_{y}$ is defined as the load when tensile reinforcement enters yielding stage. The ultimate load $F_{u}$ is defined as the maximum load in a load-deflection curve. In general, the use of the proposed strengthening scheme can increase the cracking, yielding and ultimate loads of RC beams.

Table 5. Characteristic loads of specimens.

\begin{tabular}{cccccccc}
\hline Specimen & B-C & B-O-S-A & B-A-S-A & B-A-L-A & B-A-L-1.5A & B-A-L-2A 0 & B-A-Bar \\
\hline \multirow{2}{*}{$F_{c}(\mathrm{kN})$} & 17.7 & 18.8 & 21.2 & 20.5 & 20.1 & 19.7 & 20.0 \\
& N/A & $+6.2 \%$ & $+19.8 \%$ & $+15.8 \%$ & $+10.2 \%$ & $+11.3 \%$ & $+13.0 \%$ \\
\hline \multirow{2}{*}{$F_{y}(\mathrm{kN})$} & 55.5 & 59.3 & 61.7 & 63.4 & 67.8 & 66.8 & 64.5 \\
& $\mathrm{~N} / \mathrm{A}$ & $+6.8 \%$ & $+11.2 \%$ & $+14.2 \%$ & $+22.2 \%$ & $+20.4 \%$ & $+16.2 \%$ \\
\hline \multirow{2}{*}{$F_{u}(\mathrm{kN})$} & 65.5 & 68.2 & 72.1 & 75.9 & 82.8 & 74.4 & 75.1 \\
& $\mathrm{~N} / \mathrm{A}$ & $+4.1 \%$ & $+10.1 \%$ & $+15.9 \%$ & $+26.4 \%$ & $+13.6 \%$ & $+14.7 \%$ \\
\hline
\end{tabular}

The beam strengthened with OPC matrix shows the smallest enhancement in cracking load as compared with those strengthened with AAS matrix. This is mainly attributed to less effective force transfer at the concrete-OPC matrix interface. Among the beams strengthened with AAS matrix, increasing the amount of fabric reduces the enhancement in cracking load. This is because that the force in the strengthening system is mainly taken by the matrix before cracking. As a result, the cracking load of strengthened beams highly depends on the property of matrix. The beams strengthened with a larger amount of fabric (e.g. specimens B-A-L-1.5 $\mathrm{A}_{0}$ and $\mathrm{B}-\mathrm{A}-\mathrm{L}-2 \mathrm{~A}_{0}$ ) possess a smaller area of matrix in the strengthening layer, leading to a smaller enhancement in cracking load.

As the formation of tensile cracks, forces in the tensile zone were mainly taken by steel rebars 
in the concrete and the fabrics inside the strengthening layer. Thus, yielding load $F_{y}$ highly depends on the amount of reinforcements embedded in the matrix. Consequently, the beams strengthened with a higher amount of fabric exhibits a larger enhancement ratio in the yielding load. Similarly, specimen B-O-A-A 0 exhibits the lowest improvement due to the poor bond between OPC matrix and concrete. Comparing the yielding load of specimens B-A-S-A 0 with $\mathrm{B}-\mathrm{A}-\mathrm{L}-\mathrm{A}_{0}$, it can be found that the large-section bundle in the strengthening system is more effective in enhancing the yielding load of beams. The yielding load of specimen B-A-Bar is increased by $16.2 \%$, which is lower than that of specimen B-A-L-1.5A 0 . With a similar equivalent reinforcement ratio in the strengthening layer, the carbon fabrics are more effective than CFRP bars in improving the yielding load of strengthened beam.

The ultimate load $F_{u}$ of strengthened beams is influenced by both the amount of reinforcement inside matrix and the failure mode. For instance, the beam strengthened with OPC matrix (i.e. specimen $\mathrm{B}-\mathrm{O}-\mathrm{S}-\mathrm{A}_{0}$ ) shows the smallest enhancement in ultimate load as it failed in premature end-debonding of strengthening layer. With rupture of fabric, the beams strengthened with AAS matrix generally show a higher improvement in ultimate load. Among them, increasing the amount of fabric (i.e. specimen B-A-L-1.5 $\mathrm{A}_{0}$ ) enhances the improvement in ultimate load as the end-debonding of strengthening layer was prevented. However, further increasing the amount of fabric (i.e. specimen B-A-L-2A0) has a negative impact on the ultimate load of the beam as debonding between fabric and matrix occurred. The enhancement of ultimate load for the beam strengthened with CFRP bars is less than that of specimen B-A-L-1.5A $\mathrm{A}_{0}$, due to the early debonding at the matrix-concrete interface.

\subsection{Stiffness}

The elastic stiffness $K_{e}$ and cracking stiffness $K_{c}$ are defined as the slope of load-deflection curve before and after the first cracking [35] and are tabulated in Table 6 . All the strengthened beams possess higher $K_{e}$ and $K_{c}$ than control specimen.

Table 6. Elastic stiffness and cracking stiffness of RC beams.

\begin{tabular}{cccccccc}
\hline Specimen & B-C & B-O-S-A $_{0}$ & B-A-S-A $_{0}$ & B-A-L-A $_{0}$ & B-A-L-1.5A $_{0}$ & B-A-L-2A $_{0}$ & B-A-Bar $^{-}$ \\
\hline$K_{e}$ & 14.6 & 23.7 & 25.9 & 24.8 & 23.1 & 16.2 & 19.6 \\
$(\mathrm{kN} / \mathrm{mm})$ & $\mathrm{N} / \mathrm{A}$ & $+62.3 \%$ & $+77.4 \%$ & $+69.9 \%$ & $+58.5 \%$ & $+11.0 \%$ & $+34.2 \%$ \\
\hline$K_{c}$ & 5.8 & 6.0 & 6.0 & 5.9 & 6.2 & 6.3 & 6.2 \\
$(\mathrm{kN} / \mathrm{mm})$ & $\mathrm{N} / \mathrm{A}$ & $+3.4 \%$ & $+3.4 \%$ & $+1.7 \%$ & $+6.9 \%$ & $+8.6 \%$ & $+6.9 \%$ \\
\hline
\end{tabular}

The elastic stiffness $K_{e}$ of strengthened beams mainly relies on the characteristics of matrix in the strengthening layer. For the beams strengthened with the same amount of fabric, the elastic stiffness of beam strengthened with OPC matrix is slightly lower than that with AAS matrix, which is probably caused by the lower stiffness of the fabric reinforced OPC matrix as compared to the fabric reinforced AAS matrix. For the beams strengthened with AAS matrix, adopting more fabric in the strengthening system decreases their elastic stiffness. This is caused by the decreased area of matrix in the strengthening scheme. In addition, specimen B-A-L-2A 0 shows the smallest enhancement in elastic stiffness of $11.0 \%$, due to the over-placement of fabric that reduced the force transferring between fabric and matrix layers. With a similar 
equivalent reinforcement ratio, specimen B-A-Bar exhibits the smaller elastic stiffness $K_{e}$ than specimen B-A-L-1.5A0.

The strengthened beams show a similar improvement in cracking stiffness ranging from $1.7 \%$ to $8.6 \%$. For the beams strengthened with AAS matrix, cracking stiffness $K_{c}$ increases as the amount of fabric in the strengthening layer increases. The highest improvement in cracking stiffness is attained at $8.6 \%$ for specimen B-A-L-2A 0 . The cracking stiffness of specimens B$\mathrm{A}-\mathrm{L}-1.5 \mathrm{~A}_{0}$ and $\mathrm{B}-\mathrm{A}-\mathrm{Bar}$ tends to be consistent as these two specimens have similar equivalent reinforcement ratio in the strengthening scheme.

\subsection{Strain of tensile steel reinforcement}

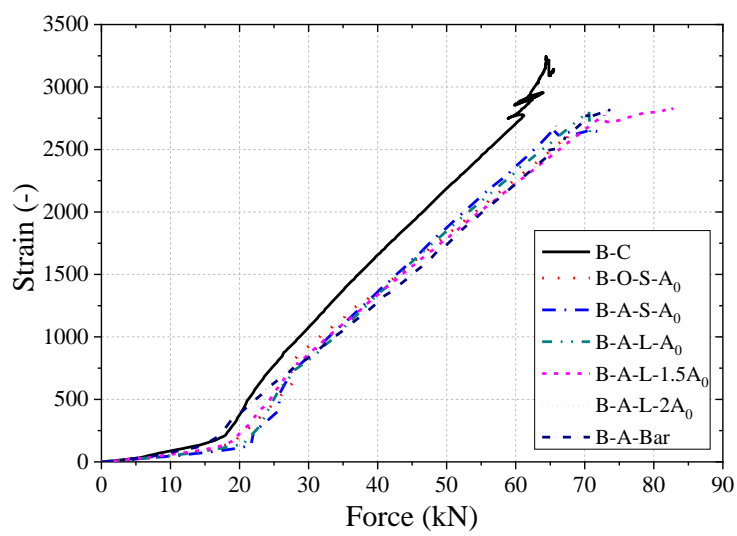

Figure 11. Relation of strain of reinforcement to force of beams.

Figure 11 shows the relationship of the applied vertical force versus the strain of tensile reinforcement at the mid-span of beam. With the strengthening systems applied, strains of tensile reinforcements in the beams subjected to the same applied force are obviously reduced as compared with that of control specimen. For instance, the strains of reinforcements for the strengthened beams are reduced by nearly $20 \%$ at the vertical load of $65.0 \mathrm{kN}$. Under a smaller vertical force below $15.0 \mathrm{kN}$, there is no significant difference in the strain of reinforcements for all the specimens. This indicates the effectiveness of the strengthening system is not evident before the occurrence of first crack in the beams. As the applied vertical load increases, the strain of reinforcements in control specimen increases faster than that in the strengthened specimens. It indicates that the strengthening layer installed on the beam can decrease the strain of reinforcement, particularly for specimens subjected to a high load. The strain of reinforcements in the strengthened beams tends to be similar, indicating that the different flexural responses of strengthened beams are mainly caused by the fabric reinforced AAS matrix. However, the strain of reinforcements for the beam strengthened with CFRP bars is slightly lower than that of other strengthened beams. This reflects that CFRP bars in the strengthening system seem to be more effective in diverging the force taken by steel reinforcements of beam.

\section{Theoretical analysis}

To further analyse the efficiency of fabric in the strengthening system, an analytical model based on sectional analysis is proposed. The model assumes a plane strain distribution. The 
concrete properties are determined based on the Chinese code GB50010 [36]. The steel reinforcement and carbon fabric are assumed to be elastic-perfectly-plastic and elastic-brittle. The analytical model is developed for the strengthened beams failed in the mode of fabric rupture. Although debonding between matrix and concrete is another common failure mode, it can be prevented by providing proper anchorage systems. Moreover, rupture of fabrics in the strengthened beams is preferable as it reflects a higher utilization of fabric in the strengthening system. The yielding load $F_{y}$ and ultimate load $F_{u}$ were predicted by the developed model and compared with the test results. Based on the comparison, the efficiency of fabric embedded in matrix of the proposed strengthening system is evaluated and discussed.

\subsection{Analytical model for yielding and ultimate states}
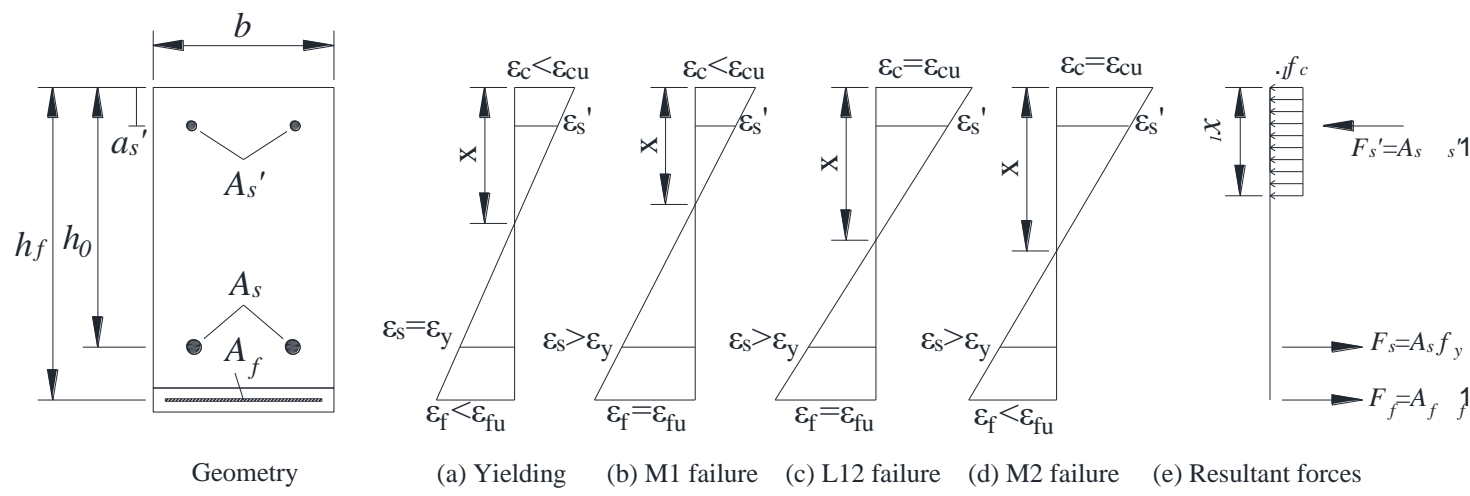

(a) Yielding

(b) M1 failure

(c) L12 failure

(d) M2 failure

(e) Resultant forces

Figure 12. Strain distribution at failure modes and boundary limits.

To predict the yielding and ultimate loads, a cross-sectional analysis of RC beams strengthened with fabric reinforced AAS matrix was performed. Figure 12 shows the strain distribution of cross sections under different strain states. The yielding state is characterised by the yielding of tensile reinforcement, and the yielding load can be calculated accordingly. There are two failure modes of strengthened beams under the ultimate state, depending on the properties of concrete and the amount of fabric. If the concrete strength is high enough but the amount of fabric placed is insufficient, failure of section could happen with fabric rupture (i.e. failure mode M1 in Figure 12). If concrete reaches the ultimate strain prior to the rupture of fabric, the failure initiates at the compression zone with concrete crushing (i.e. failure mode M2 in Figure 12). This failure normally occurs for the beam with a large amount of fabric. There also exists a boundary case when the concrete crushing and fabric rupture simultaneously occur at the cross section. In this case, the depth of concrete compression zone can be calculated by Eq. (1).

$$
x_{L 12}=\varepsilon_{c u} h_{f} /\left(\varepsilon_{c u}+\varepsilon_{f u}\right)
$$

where $x_{L 12}$ is the depth of concrete compressive zone, $h_{f}$ is the depth of fabric, $\varepsilon_{f u}$ and $\varepsilon_{c u}$ are the rupture strain of fabric and the ultimate compressive strain of concrete, respectively. By imposing force equilibrium, the area of fabric $A_{f L}$ can be calculated by Eq. (2).

$$
A_{f L 12}=\left(0.8 f_{c} x_{L 12} b+A_{s}{ }^{\prime} \sigma_{s}{ }^{\prime}-A_{s} f_{y}\right) / f_{f u}
$$

where $f_{c}, f_{y}$ and $f_{f u}$ are the compressive strength of concrete, the yielding strength of reinforcement and the rupture strength of fabric, respectively. $A_{s}$ and $A_{s}$ ' are the areas of 
reinforcements in the tensile and compression zones, respectively. $b$ is the width of cross section. $\sigma_{s}{ }^{\prime}$ is the stress of compression reinforcement. Based on the geometry and material properties of specimens tested in this study, $A_{f L 12}$ is calculated and is equal to $31.79 \mathrm{~mm}^{2}$. Theoretically, fabric rupture occurs if the fabric area is lower than $A_{f L 12}$, while concrete crushing happens in the converse case.

For a beam strengthened by fabric reinforced AAS matrix, the strains of concrete, reinforcement and fabric are correlated by the depth of concrete compression zone $x$. Based on force equilibrium at the section, $x$ can be computed based on Eq. (3).

$$
\alpha_{1} f_{c} \beta_{1} x b+F_{s}{ }^{\prime}-F_{s}-F_{f}=0
$$

where $\alpha_{1}$ and $\beta_{1}$ are the parameters depending on the compressive strain of concrete at the top surface. $F_{s}, F_{s}^{\prime}$ and $F_{f}$ are the resultant forces of tensile reinforcement, compressive reinforcement and fabric, respectively. Afterward, the bending moment $M$ at the yielding state or the ultimate state can be calculated by Eq. (4).

$$
M=\alpha_{1} f_{c} \beta_{1} x b\left(h_{f}-\beta_{1} x / 2\right)+F_{s}{ }^{\prime}\left(h_{f}-a_{s}{ }^{\prime}\right)-F_{s}\left(h_{f}-h_{0}\right)
$$

where $h_{0}$ is the distance from the tensile reinforcements to the top of section. For a beam failed with concrete crushing, $\alpha_{1}$ and $\beta_{1}$ can be taken as 1.0 and 0.8 , respectively. For other cases, $\alpha_{1}$ and $\beta_{1}$ can be determined in accordance with Eqs. (5)-(8) [37].

$$
\begin{gathered}
\alpha_{l}=k_{1} / \beta_{1} \\
\beta_{1}=2 k_{2} \\
k_{1}= \begin{cases}\frac{\varepsilon_{c}}{\varepsilon_{c 0}}-\frac{\varepsilon_{c}^{2}}{3 \varepsilon_{c 0}^{2}} & \text { if } \varepsilon_{c}<\varepsilon_{c 0} \\
1-\frac{\varepsilon_{c}}{3 \varepsilon_{c 0}} & \text { if } \varepsilon_{c 0}<\varepsilon_{c}<\varepsilon_{c u}\end{cases} \\
k_{2}= \begin{cases}\frac{4 \varepsilon_{c 0}-\varepsilon_{c}}{12 \varepsilon_{c 0}-\varepsilon_{c}} & \text { if } \varepsilon_{c}<\varepsilon_{c 0} \\
1-\frac{3-\varepsilon_{c 0}^{2} / 2 \varepsilon_{c}^{2}}{6-2 \varepsilon_{c 0} / \varepsilon_{c}} & \text { if } \varepsilon_{c 0}<\varepsilon_{c}<\varepsilon_{c u}\end{cases}
\end{gathered}
$$

where $\varepsilon_{c 0}$ is the compressive strain of concrete at the peak stress, and $\varepsilon_{c u}$ is the ultimate compressive strain of concrete.

\subsection{Comparison between prediction and test results}




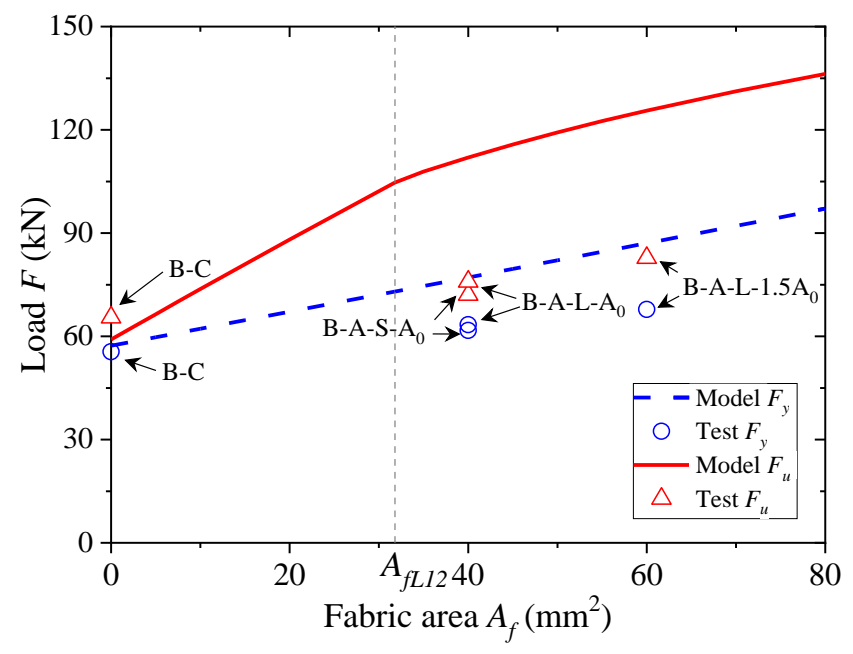

Figure 13. Theoretical values of $F_{y}$ and $F_{u}$ under different $A_{f}$.

Figure 13 shows the predicted yielding and ultimate loads of beams strengthened with different amounts of fabric. The yielding and ultimate loads of the tested RC beams are also plotted. Theoretically, the yielding load of beam strengthened by fabric reinforced AAS matrix increases linearly with the area of fabric. On the other hand, the ultimate load of strengthened beam increases linearly as the amount of fabric increases up to $A_{f L 12}$. When more fabrics are provided (i.e. $A_{f}>A_{f L 12}$ ) in the strengthening system, the ultimate load of beam increases nonlinearly as it is dominated by the properties of concrete.

As seen in Figure 13, the developed model generally overestimates the yielding and ultimate loads of the three strengthened beam specimens. The yielding load $F_{y}$ is slightly overestimated by about $10 \%$. However, the predicted ultimate loads of the strengthened beams are much higher than their test results. This is mainly attributed to that fabric bundles in the strengthening system are hard to work simultaneously. It means that the amount of effective fabrics in strengthening system for resisting force is reduced, although the assigned $A_{f}$ in the strengthening scheme is much larger than AfL12. Moreover, it was found that some fabric bundles suffered a local slippage before rupture during the test, which further decreases the utilization of fabric strength. These explanations are also evidenced by that the failure of strengthened beams initiated with fabric rupture rather than concrete crushing.

To quantify the effectiveness of fabric bundles in the strengthening scheme, an efficiency factor $\mu$ defined as the ratio of $A_{f m}$ to $A_{f}$ is proposed. $A_{f m}$ is calculated with the proposed analytical model based on the targeted yielding and ultimate loads, while $A_{f}$ is the actual area of fabric used in the strengthened beams. Table 7 summarizes the calculation of efficiency factor for the three strengthened beams. In general, the efficiency factor of fabric in the strengthening system ranges from 0.2 to 0.4 . For the beams strengthened by the optimized strengthening system, two efficiency factors of 0.35 and 0.25 for fabrics are obtained for estimating the yielding and ultimate loads, respectively. They can also be adopted in the design of fabric reinforced AAS matrix-strengthened RC beams. 
Table 7. Calculation of efficient factor $\mu$ for fabric area in strengthened specimens.

\begin{tabular}{lccccccc}
\hline \multirow{2}{*}{ Specimen } & $\begin{array}{c}A_{f} \\
\left(\mathrm{~mm}^{2}\right)\end{array}$ & $\begin{array}{c}\text { Load from } \\
\text { test }(\mathrm{kN})\end{array}$ & $\begin{array}{c}\text { Required } \\
A_{f m}\left(\mathrm{~mm}^{2}\right)\end{array}$ & $\mu$ & $\begin{array}{c}\text { Load from } \\
\text { test }(\mathrm{kN})\end{array}$ & $\begin{array}{c}\text { Required } \\
A_{f m}\left(\mathrm{~mm}^{2}\right)\end{array}$ & $\mu$ \\
\hline B-A-S-A 0 & 40 & 61.7 & 9.0 & 0.23 & 72.1 & 8.9 & 0.22 \\
\hline B-A-L-A 0 & 40 & 63.4 & 12.4 & 0.31 & 75.9 & 11.5 & 0.29 \\
\hline B-A-L-1.5A $\mathrm{A}_{0}$ & 60 & 67.8 & 21.3 & 0.36 & 82.8 & 16.3 & 0.27 \\
\hline
\end{tabular}

\section{Conclusions}

This paper investigated the flexural behaviour of $\mathrm{RC}$ beams strengthened by carbon fabric or FRP bars reinforced AAS matrix. The influences of matrix type, fabric bundle size, total fabric amount and matrix reinforcement form on the effectiveness of the proposed strengthening method were examined. Seven RC beams, including one control specimen and six strengthened specimens, were tested under four-point bending. Based on the test results, the following conclusions can be drawn.

(1) The externally bonded CFRP fabric or bars reinforced AAS matrix is effective in enhancing the flexural performance of RC beams. The ultimate load and flexural elastic stiffness of $\mathrm{RC}$ beams strengthened with $1.5 \mathrm{~A} 0$ fabric are increased by $26.4 \%$ and $58.5 \%$, respectively. The proposed strengthening method can also reduce the strain of tensile reinforcements in $\mathrm{RC}$ beams by around $20 \%$ at the advanced stage of loading.

(2) Replacing OPC matrix by AAS matrix in the strengthening system shifts the failure mode from end-debonding of strengthening layer to slippage combined with rupture of fabric. The strength of CFRP fabric is better utilized in the strengthening method, leading to improved loading capacities and stiffness for RC beams.

(3) Large bundle fabric in the strengthening system is more effective in enhancing the flexural behaviour of RC beams. Progressive rupture of fabric in the strengthening system tends to restrain the total tensile force sustained by the small-section fabric.

(4) Increasing the amount of fabric in the strengthening system decreases the cracking load and elastic stiffness of RC beams, but enhances their yielding load, ultimate load, and cracking stiffness. The former reduction is mainly dominated by the net area of matrix, while the latter is contributed from the fabric in the strengthening system. However, excessive fabric would induce interlaminate debonding between fabric layer and matrix, and consequently decreases the effectiveness of the strengthening system.

(5) The beam strengthened with CFRP bars reinforced AAS matrix exhibits the higher stiffness and comparable ultimate load as compared to that with equivalent amount of fabric. As it fails in premature end-debonding of strengthening layer, proper anchorage of CFRP bars reinforced AAS matrix can be provided to further utilize the strength of CFRP bars.

(6) The proposed analytical model based on sectional analysis overestimates the yielding and ultimate loads of RC beams strengthened by fabric reinforced AAS matrix. Two efficiency factors of 0.35 and 0.25 , taking account of the area of effective fabric, are obtained and 
recommended to determine the yielding and ultimate loads of strengthened beams, respectively.

\section{Acknowledgement}

The authors wish to acknowledge the financial support from the National Natural Science Foundation of China - Young Scientists (No.: 51708306), Zhejiang Provincial Natural Science Foundation of China (No.: LGF19E080008) and Ningbo Municipal Bureau of Science and Technology (No.: 2019B10048). The Zhejiang Provincial Department of Science and Technology is also acknowledged for this research under its Provincial Key Laboratory Programme (No.: 2020E10018).

\section{References}

[1] A. Siddika, M.A. Al Mamun, R. Alyousef, Y.H.M. Amran, Strengthening of reinforced concrete beams by using fiber-reinforced polymer composites: A review, J. Build. Eng. 25 (2019) 100798.

[2] H. Akbarzadeh Bengar, A.A. Shahmansouri, A new anchorage system for CFRP strips in externally strengthened RC continuous beams, J. Build. Eng. 30 (2020) 101230.

[3] D. Y.G, Strengthening of RC beams by using sprayed concrete: experimental approach, Eng. Struct. 20 (1998) 631-643.

[4] A. Hassan, F. Aldhafairi, L.M. Abd-EL-Hafez, A.E.Y. Abouelezz, Retrofitting of different types of reinforced concrete beams after exposed to elevated temperature, Eng. Struct. 194 (2019) 420-430.

[5] L. Correia, C. Barris, P. França, J. Sena-Cruz, Effect of temperature on bond behavior of externally bonded FRP laminates with mechanical end anchorage, J. Compos. Constr. 23 (2019) 04019036.

[6] S.T. Smith, J.G. Teng, FRP-strengthened RC beams. II: Assessment of debonding strength models, Eng. Struct. 24 (2002) 397-417.

[7] S.M. Raoof, L.N. Koutas, D.A. Bournas, Textile-reinforced mortar (TRM) versus fibrereinforced polymers (FRP) in flexural strengthening of RC beams, Constr. Build. Mater. 151 (2017) 279-291.

[8] U. Ebead, Hybrid externally bonded/mechanically fastened fiber-reinforced polymer for RC beam strengthening, ACI Struct. J. 108 (2011) 669-678.

[9] M.M. Rahman, M.Z. Jumaat, M.A. Rahman, I.M.I. Qeshta, Innovative hybrid bonding method for strengthening reinforced concrete beam in flexure, Constr. Build. Mater. (2015).

[10] C. Chen, X. Wang, L. Sui, F. Xing, X. Chen, Y. Zhou, Influence of FRP thickness and confining effect on flexural performance of HB-strengthened RC beams, Compos. Part B Eng. 161 (2019) 55-67.

[11] P.P. Diotallevi, L. Landi, M. Guiduzzi, Experimental tests of RC beams strengthened with composite materials using IPN water-based resins, Mater. Struct. Constr. 50 (2017) 1-18.

[12] S. Majhi, A. Mukherjee, A.F. Spadaccini, Thermal performance of an alkali-activated paste for bonding fibre sheets with concrete, Compos. Part B Eng. 162 (2019) 43-53.

[13] H.Y. Zhang, H.R. Lv, V. Kodur, S.L. Qi, Comparative fire behavior of geopolymer and 
epoxy resin bonded fiber sheet strengthened RC beams, Eng. Struct. 155 (2018) 222-234.

[14] L.N. Koutas, Z. Tetta, D.A. Bournas, T.C. Triantafillou, Strengthening of concrete structures with textile reinforced mortars: State-of-the-art review, J. Compos. Constr. 23 (2018) 03118001 .

[15] Y. Li, S. Yin, J. Dai, M. Liu, Numerical investigation on the influences of different factors on the seismic performance of TRC-strengthened RC columns, J. Build. Eng. 30 (2020) 101245. [16] A. Peled, S. Sueki, B. Mobasher, Bonding in fabric-cement systems: Effects of fabrication methods, Cem. Concr. Res. 36 (2006) 1661-1671.

[17] A. Peled, Z. Cohen, Y. Pasder, A. Roye, T. Gries, Influences of textile characteristics on the tensile properties of warp knitted cement based composites, Cem. Concr. Compos. 30 (2008) 174-183.

[18]A. Nobili, F.O. Falope, Impregnated carbon fabric-reinforced cementitious matrix composite for rehabilitation of the finale emilia hospital roofs: case study, J. Compos. Constr. 21 (2017) 05017001.

[19] S.P. Yin, S.L. Xu, F. Wang, Investigation on the flexural behavior of concrete members reinforced with epoxy resin-impregnated textiles, Mater. Struct. 48 (2015) 153-166.

[20]B.T. Truong, T.T. Bui, A. Limam, A. Si Larbi, K. Le Nguyen, M. Michel, Experimental investigations of reinforced concrete beams repaired/reinforced by TRC composites, Compos. Struct. 168 (2017) 826-839.

[21]Z.R. Aljazaeri, M.A. Janke, J.J. Myers, A novel and effective anchorage system for enhancing the flexural capacity of RC beams strengthened with FRCM composites, Compos. Struct. 210 (2019) 20-28.

[22] M.R. Irshidat, A. Al-Shannaq, Using textile reinforced mortar modified with carbon nano tubes to improve flexural performance of RC beams, Compos. Struct. 200 (2018) 127-134.

[23] A. Fernández-Jiménez, J.G. Palomo, F. Puertas, Alkali-activated slag mortars: Mechanical strength behaviour, Cem. Concr. Res. 29 (1999) 1313-1321.

[24] M.H. Mahmoud, M.T. Bassuoni, Performance of concrete with alkali-activated materials and nanosilica in acidic environments, J. Mater. Civ. Eng. 31 (2019) 04019009.

[25] A.M. Rashad, M.H. Khalil, A preliminary study of alkali-activated slag blended with silica fume under the effect of thermal loads and thermal shock cycles, Constr. Build. Mater. 40 (2013) $522-532$.

[26] C. Menna, D. Asprone, C. Ferone, F. Colangelo, A. Balsamo, A. Prota, R. Cioffi, G. Manfredi, Use of geopolymers for composite external reinforcement of RC members, Compos. Part B Eng. 45 (2013) 1667-1676.

[27] M.H. Al-Majidi, A.P. Lampropoulos, A.B. Cundy, O.T. Tsioulou, S. Alrekabi, Flexural performance of reinforced concrete beams strengthened with fibre reinforced geopolymer concrete under accelerated corrosion, Structures. 19 (2019) 394-410.

[28] S. Kumar, R. Kumar, S.P. Mehrotra, Influence of granulated blast furnace slag on the reaction, structure and properties of fly ash based geopolymer, J. Mater. Sci. 45 (2010) 607615.

[29] G. Fang, W.K. Ho, W. Tu, M. Zhang, Workability and mechanical properties of alkaliactivated fly ash-slag concrete cured at ambient temperature, Constr. Build. Mater. 172 (2018) 
476-487.

[30] L. Zhen, M.A.P. Lara, J.E. Bolander, Restraining effects of fibers during non-uniform drying of cement composites, Cem. Concr. Res. 36 (2006) 1643-1652.

[31] M. Deng, Z. Dong, C. Zhang, Experimental investigation on tensile behavior of carbon textile reinforced mortar (TRM) added with short polyvinyl alcohol (PVA) fibers, Constr. Build. Mater. 235 (2020).

[32] K. Zhang, Q. Sun, The use of wire mesh-polyurethane Cement (WM-PUC) composite to strengthen RC T-beams under flexure, J. Build. Eng. 15 (2018) 122-136.

[33] A.C.I. 544, 544.1R-96: Report on fiber reinforced concrete (Reapproved 2009), Tech. Doc. (n.d.).

[34] S. De Santis, G. De Felice, Steel reinforced grout systems for the strengthening of masonry structures, 134 (2015) 533-548.

[35] J. Sheng, S.P. Yin, S.L. Xu, Z.Y. Jin, Experimental and theoretical investigations on crack spacing and stiffness of textile-reinforced concrete-strengthened reinforced concrete beams, Adv. Struct. Eng. 21 (2018) 1696-1707.

[36] China Building Industry Press, Code for design of concrete structures. GB50010. 2015th ed., China Building Industry Press, Beijing, 2015.

[37] S. Yin, S. Xu, H. Lv, Flexural behavior of reinforced concrete beams with TRC tension zone cover, J. Mater. Civ. Eng. 26 (2014) 320-330. 